\title{
Large-scale and High-resolution Flood Risk Model for Japan
}

\author{
Anongnart Assteerawatt ${ }^{1, a}$, Dimosthenis Tsaknias ${ }^{1}$, Frederic Azemar ${ }^{1}$, Sourima Ghosh ${ }^{1}$ and Arno Hilberts ${ }^{1}$ \\ ${ }^{1}$ Risk Management Solutions, Inc., Peninsular House, 30 Monument Street, London EC3R 8NB, UK
}

\begin{abstract}
Japan has experienced several catastrophic flood events causing extensive damage to property and the national economy due to its topography, geography, and climate. Steep and short rivers, frequent typhoons and torrential rains, extremely high concentration of people and assets in flood-prone areas, and intensive human intervention subject the country to frequent flood disasters. Risk Management Solutions (RMS) has developed a stochastic inland flood model as part of its Japan Typhoon Model to assess flood risk due to typhoon for the (re)insurance industry. The RMS flood risk model consists of i) a precipitation-driven flood hazard module, ii) a building-level exposure module, iii) a component-based vulnerability module and iv) a financial module. The flood model is driven by 105,000 years of continuously simulated precipitation accounting for typhoon and non-typhoon precipitation. Rainfall-runoff and routing models, fluvial- and pluvial-inundation models, and probabilistic defence failures are included in the flood hazard module to obtain a realistic view of flood risk. By combining a large, country-level stochastic dataset with a high-resolution grid $(\sim 40 \mathrm{~m})$ for flood inundation modeling, and building level exposure data and hundreds of unique component-based vulnerability types, a comprehensive view of flood risk is provided on both local and aggregate levels, The financial module accounts for insured risk from different financial contracts.
\end{abstract}

\section{Introduction}

Japan's historical floods have caused severe damages to property, tothe national economy, and have resulted in thousands of deaths. Its topography, geography, and climate subject the country to floods on a frequent basis. In addition, about half of the population and approx. $75 \%$ of the assets in Japan are concentrated in flood-prone areas. A fraction of these areas are below sea level such as the three largest bays, Tokyo, Osaka and Nagoya. Hence, construction of flood mitigation structures(i.e., flood defences/levees, reservoirs and retention basins) has been carried out in a considerably pace over the last decades. Despite significant investment in flood control structures, there have still been several severe flood events, but with considerably fewer loss of life. As an example of that: In the recent flood event from tropical storm Etau in September 2015, at least eight people were killed and it caused JPY30 billion (USD250 million) in insured loss (economic losses were even greater). Additionally, a study by Okada et al. [1] showed that the insured loss for residential property alone could reach up to around JPY1 trillion (USD12.5 billion) if a Tokyo flood similar to Typhoon Kathleen 1947 would happen now.

In order to assess financial losses, catastrophe (CAT) risk models have been widely used in (re)insurance industries. The CAT risk models represent financial losses using stochastic event sets of over tens of thousands of years on a large-scale domain (i.e., country scale or larger). Hence, spatio-temporal correlations of loss across the entire domain and also extreme events (i.e., low frequency and high severity events) can be captured. The RMS inland flood CAT risk model consists of i) a precipitation-driven flood hazard module, ii) a building-level exposure module, iii) a component-based vulnerability module and iv) a financial module.

This paper presents all components of the RMS Japan inland flood risk focusing on the hazard module in which stochastic flood footprints are generated. The exposure and the vulnerability modules are briefly discussed and later the results and conclusion are presented.

\section{RMS flood hazard module}

Flood risk model present here is a part of the RMS Japan Typhoon Risk Model which includes 3 perils: wind, inland flood, and coastal flood. For inland flood, we perform a 105,000 years long continuous simulation to capture antecedent conditions of runoff, discharge and soil moisture. This is required to assess both fluvial and pluvial flood risk.

The framework of the flood hazard module developed for Japan is presented in Figure 1. The flood model is driven by a continuous stochastic precipitation set from combined typhoons and torrential rainfalls. Based on the stochastic precipitation set, surface runoff and river discharge are simulated in a rainfall runoff model (RRM) and a routing model respectively and later used as inputs

\footnotetext{
${ }^{a}$ Corresponding author: anongnart.assteerawatt@,rms.com
} 
in pluvial and fluvial inundation models to create undefended flood maps. A probabilistic type of defence failure is considered to obtain a realistic flood footprint for each event in the stochastic set. The precipitation, RRM and routing models are calibrated based on observed data described in the input data section. The framework of the RMS flood hazard module developed for Japan is similar to that of other RMS flood models [2, $3]$.

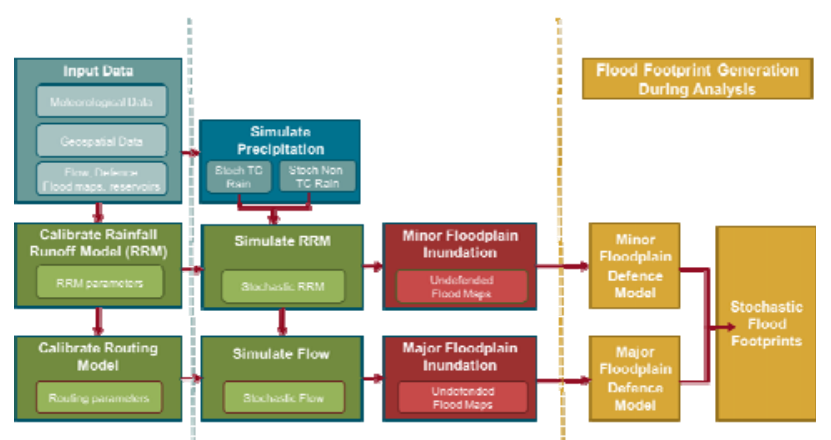

Figure 1. RMS inland flood hazard module.

\subsection{Input data}

The model requires main input data as follows:

- Meteorological data: precipitation and other atmospheric forcings (temperature, wind speed, surface pressure, longwave and shortwave radiation, specific humidity).

- Geospatial data: digital elevation data and river networks.

- Typhoon track set, flow, defence and reservoir data.

- Additional data for model validation: such as authority flood maps.

For all these data sources we compared various different alternatives and selected the ones which best meet our specific requirements. . Due to the steep and short rivers and extreme rainfall intensity in Japan, runoff and river flow during a flood event can vary significantly on short time-scales. To represent these peaks, the flood model requires hourly input data for precipitation, atmospheric forcings and flow data.

For precipitation, we downscaled Aphrodite-JP $V 1207$ daily gridded data $(5 \mathrm{~km})$ from $1984-2010$ provided by the Asian Precipitation-Highly-Resolved Observational Data Integration Towards Evaluation of Water Resources [4] to hourly data using 1,300 hourly rainfall $A M e D A S$ provided by Japan Meteorological Agency (JMA). For other forcings, we uses the Climate Forecast System Reanalysis (CFSR) meteorological forcings data from 1984-2010 provided by National Centers for Environmental Prediction (NCEP). The historical typhoon track required for the typhoon rain model is derived from derived from JMA and JTWC (Joint Typhoon Warning Centre) data. The digital elevation data is derived from two data sources provided by the Geospatial Information Authority of Japan (GSI): a $5 \mathrm{~m}$ airborne altimetric LiDAR (Light Detection and Ranging) for major populated areas and a $10 \mathrm{~m}$ topological map of 1:25,000 with $10 \mathrm{~m}$ contour intervals. Both DTM sources are resampled to $50 \mathrm{~m}$ to match the resolution of the flood hazard module before merging. After careful checking the total hourly 1,200 river gauges provided by the Ministry of Land, Infrastructure, Transport and Tourism (MLIT), around 400 river gauges are used a model calibration/validation. The model uses a river network with an approximate length of 20,000 km., and the river location is corrected where needed by comparison to Google Earth. We explicitly model over 30 key reservoirs/lakes from the Global Reservoir and Dam (GRanD) database (Global Water System project, Bonn, Germany).

\subsection{Precipitation and forcings}

A stochastic set of 105,000 years of precipitation and atmospheric forcings (temperature, wind speed, surface pressure, shortwave and longwave radiation and the specific humidity) are simulated. We separate the precipitation in Japan in two main components: tropical cyclone (TC) precipitation and non-tropical Cyclone (non-TC) precipitation. In this work, the TC-rain is a main driver of our Japan Typhoon Flood. The RMS TCrain model is an in-house model [5] which is partially based on R-CLIPER, but while including rain enhancement due to orography and landfall, the asymmetry pattern of tropical cyclone rain, extratropical transitioning, and Predecessor Rain Events (PRE). The TC-rain model is parameterized using typhoon tracks from Hurricane Databases (HURDAT) and rain data from Tropical Rainfall Measuring Mission (TRMM) and Aphrodite. Figure 2 shows a comparison of Typhoon Tokage 2004 daily rainfall intensity between observed rainfall (Aphrodite) and simulated rainfall. The non-TC rain is generated using principal component analysis (PCA) based on the analysis of 27-years (1984-2010) of precipitation data obtained from Aphrodite. The TC precipitation is then merged with the non-TC precipitation to generate a set of 105,000 years of precipitation. For the remaining forcings, the stochastic forcings are generated using an analogous mapping method.
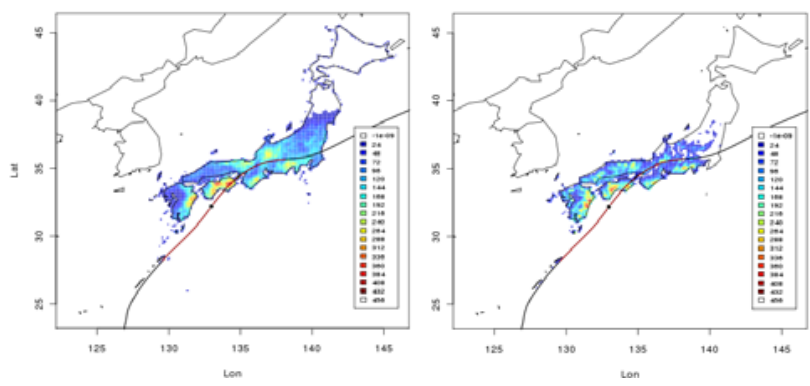

Figure 2. Observed (left) and simulated (right) rain intensity for Typhoon Tokage 2004

\subsection{Rainfall-Runoff and Routing Model}

Runoff and flow are simulated separately using a rainfall-runoff model (RRM) and a routing model. The RRM models the most relevant hydrological processes in the water cycle (e.g., snow water storage, 
evapotranspiration, and subsurface flow). In a snow model, the separation of snow and rain from incoming precipitation, snow storage and snow melt is calculated at each time step. The evapotranspiration model is based on the Penman-Monteith equation (as a function of atmospheric forcings), and a canopymodel is included as well. The subsurface flow model is a semi-distributed model based on TOPMODEL [6]. Areas within a catchment that are hydrologically similar are grouped together using a topographic index, which represent the combined effect of terrain slope and accumulation area, and vertical water fluxes between three zones (root, unsaturated and saturated zones) are calculated dynamically.

The routing model is based on the MuskingumCunge approach [7, 8] and integrates simulation of reservoir operation modified from the work presented by Hanasaki et al. [9] to ensure the peak discharge during a flood event is correctly represented. An operating rule is determined for each reservoir depending on reservoir storage capacity, simulated current inflow and monthly inflow.

The RRM and routing models were calibrated separately using the multi-objective evolutionary Nondominated Sorting Genetic Algorithm II [10] to minimize the root mean square error (RMSE), the RMSE for high flow and the bias. Although the challenging in Japanese river discharge which can be varied significantly within the order of hours and has a ratio of peak to normal flow higher than 100 times, the RRM and routing models still perform well across the domain. The calibration resulted in r-squared (coefficient of determination) values for larger rivers and major exposure areas of greater than 0.75 , and overall greater than approximately 0.6 . Figure 3 shows the spatial distribution of the r-squared values from routing calibration.

The calibrated RRM and routing models are then run with the input from the stochastic precipitation and forcing simulations to create a time series of 105,000 years of discharge and surface runoff. Next, the stochastic discharge and runoff are used to drive the inundation model that simulates undefended flood maps for various return periods.

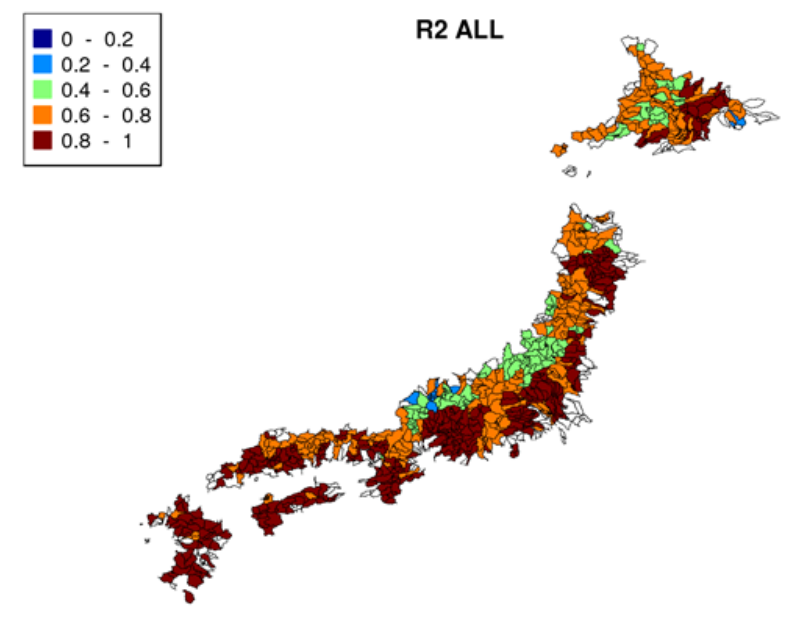

Figure 3. R-square for the routing calibration

\subsection{Inundation Model}

The inundation model is used to simulate both pluvial and fluvial flooding. The fluvial inundation captures flooding along the main river network, whereas the pluvial inundation captures flooding from minor streams (which are not a part of the river network) and also captures saturated overland flow and infiltration excess overland flow. Discharge from the river routing model feeds into the fluvial inundation model and the runoff from the RRM feeds into the pluvial inundation model. The inundation models solve the two dimensional shallow water equations (2D-SWE) using the finite volume method and a Riemann-Solver [11] on a $50 \mathrm{~m}$ grid. The 2D-SWE simulation runs in parallel on a cluster of Graphic Processing Units (GPUs) which allows for significant computational speed gains. The undefended return period maps from the inundation model are later combined with defence failure model to create a defended flood footprint (i.e., a footprint which includes the effects of defences).

\subsection{Defence Failure Model}

Flood defence information is incorporated in a defence failure model to estimate a realistic event footprint. We use a probabilistic approach to model flood defence failure based on information of Standard of Protection (SoP) of the return period flow (or rainfall) gathered from various government reports on current and future defence plans and inspection reports on defence weakness points. Detailed flood defence information is generally available for major rivers in highly populated cities. Where no detailed defence data is available, we assign defence SoP levels as a function of river size, the exposure density surrounding each river. The defence SoP is assigned to all $500 \mathrm{~m}$ river segments in the river network. For a given location along a river segment, the actual defence levels is varied from event to event. If the return period of the discharge exceeds the stochastic return period of the defence, then the model assumes that the defence fails. Adjacent defence failures are assumed to be correlated, so if a defence fails, the neighbouring defences are more likely to fail as well.

\section{RMS Exposure and Vulnerability Modules}

\subsection{Exposure Module}

Zenrin building footprint (as shown in Figure 4) and its detailed exposure database which covers $\sim 90 \%$ of total Japan exposure is the main underlying source to develop location-level economic exposure. The information of floor area, number of stories and occupancy class of each building are combined to approximate a building exposure which is then mapped to a $\sim 40 \mathrm{~m}$ grid, which is the resolution used for financial modeling. Exposures are split into residential, commercial and industrial lines of business. 


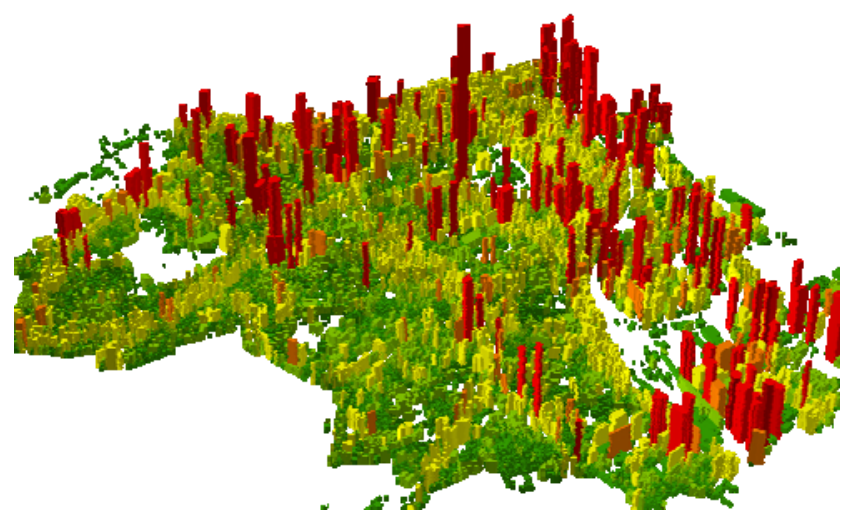

Figure 4. Example of high resolution building footprint

\subsection{Vulnerability Module}

Vulnerability to flood arises from the susceptibility of exposed elements of a building at risk to water damage. Exposed elements may include floor covering, floor base, interior wall covering, exterior wall, structural system, ceilings, electrics, plumbing etc. Flood vulnerability functions represent the relationship between the flood depth and variability in the flood loss ratio or damage ratio to buildings, contents, and their resulting loss of use, and are unique for a wide variety of building types, as shown in Figure 5. We derived these functions using an engineering component-based damage modeling approach together with published studies on flood damage, historical flood loss data and expert opinion.

The vulnerability function of different property types (e.g., residential, commercial, and industrial) and regions (e.g. urban, suburban, and rural) developed for Japan are evaluated and compared with published data from FHRC, 2010 (Flood Hazard Research Centre - Middlesex University, UK) and FRM (Flood Risk Management Program), USACE (US Army Corps of Engineers, USA).

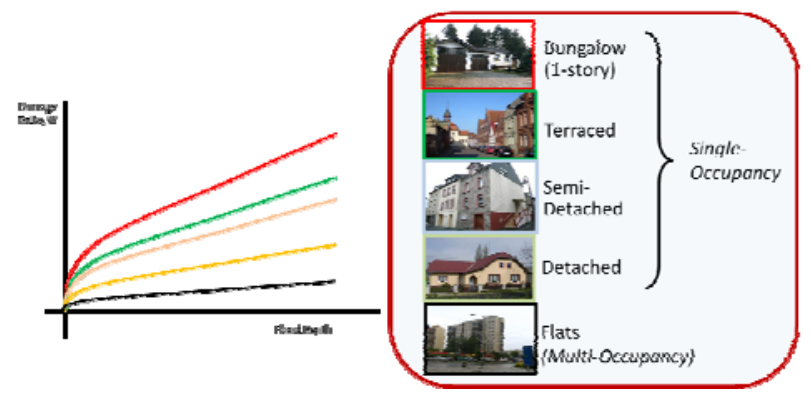

Figure 5. Example of vulnerability functions of different types of residential properties

\section{Financial Module}

The financial flood losses are calculated in the financial module where insurance structure such as takeup rates, limits, and deductible are applied. By combining information of flood depth from the hazard module, damage ratio from the vulnerability module and the exposure value, economic loss and (when applying the insurance structures) industry loss due to flood are assessed at each location (40m grid) and if needed aggregated to a desired aggregation level.

\section{Conclusion}

The RMS Japan flood risk model provides the financial tools needed to asses flood losses for the (re)insurance industry. The model combines different components i) a precipitation-driven flood hazard module, ii) a building-level exposure module, iii) a component-based vulnerability module and iv) a financial module. The hazard flood model is driven by 105,000 years of continuously simulated precipitation accounting for typhoon and non-typhoon precipitation. The flood hazard module consists of a Rainfall-runoff model, a routing model, a fluvial- and a pluvial inundation model, and a probabilistic defence failure model. By combining a large scale with high-resolution ( $40 \mathrm{~m})$ flood inundation maps, building level exposure data, and hundreds of unique component-based vulnerability types, a comprehensive view of flood risk on local as well as aggregate level can be assessed. The financial module accounts for insured risk from different financial contracts.

\section{References}

1. Okada, T., McAneney, K. J., \& Chen, K. (2011). Estimating insured residential losses from large flood scenarios on the Tone River, Japan-a data integration approach. Nat. Hazards Earth Syst. Sci, Vol. 11, 3373-3382.

2. Savina M., Hilberts A., Peiris N., Nicotina L., Rentzos P., Assteerawatt A., Zanardo S., Zovi F. (2016). RMS pan-Europe HD Flood models. Floodrisk conference 2016.

3. Jankowfsky S., Hilberts A., Mortgat C., Li S., Xu N., Mei Y., Tillmanns S., Tian Y., Yang Y. (2016). The RMS US inland flood model. Floodrisk conference 2016.

4. Kamiguchi, K., Arakawa, O., Kitoh, A., Yatagai, A., Hamada, A., \& Yasutomi, N. (2010). Development of APHROJP, the first Japanese high-resolution daily precipitation product for more than 100 years. Hydrological Research Letters, Vol. 4, 60-64.

5. Grieser J. and Jewson S. (2011). The RMS TC Rain Model. Meteorologische Zeitschrift, 21(1), 79-88.

6. Beven K. and Kirkby M. (1979). A physically based, variable contributing area model of basin hydrology. Hydroligical Sciences Bulletin 24 (1), 43-69.

7. Cunge J.A. (1969). On the subject of a flood propagation computation method (Muskingum method), Journal of. Hydraulic Research, 7(2), 205230.

8. Georgakakos K.P. (1990). A State-Space Model for Hydrologic River Routing. Water Resources Research 26(5), 827-838. 
9. Hanasaki, N., Kanae, S., \& Oki, T. (2006). A reservoir operation scheme for global river routing models. Journal of Hydrology, 327(1), 22-41.

10. Deb K., Pratap A., Agarwal S., Meyarivan T. (2002). A fast and elitist multiobjective genetic algorithm: NSGA-II, IEEE Transactions on evolutionary computation, 6(2), 182-197.

11. Gottardi, G., \& Venutelli, M. (1993). A controlvolume finite-element model for two-dimensional overland flow. Advances in Water Resources, 16(5), 277-284. 